\title{
Curcumol inhibits the viability and invasion of colorectal cancer cells via miR-30a-5p and Hippo signaling pathway
}

\author{
DAN YU ${ }^{1 *}$, HAIPING LIU ${ }^{2 *}$, JIANLI QIN $^{1}$, MENGJIE HUANGFU $^{1}$, XIAO GUAN $^{3}$, XUMEI LI $^{1}$, \\ LUWEI ZHOU $^{1}$, TONG DOU ${ }^{1}$, YISA LIU ${ }^{1}$, LIN WANG ${ }^{1}$, MINGLEI FU ${ }^{4}$, JUAN WANG $^{1,5-7}$ and XU CHEN ${ }^{1}$ \\ ${ }^{1}$ Department of Pharmacy, Guilin Medical University, Guilin, Guangxi Zhuang Autonomous Region 541001; \\ ${ }^{2}$ Science and Technology Department, Guilin Medical University, Guilin, Guangxi Zhuang Autonomous Region 541199; \\ ${ }^{3}$ Department of Pharmacology, Xiangya School of Medicine of Central South University, Changsha, \\ Hunan 410008; ${ }^{4}$ Department of Dispensary, The Second Affiliated Hospital of Guilin Medical University; \\ ${ }^{5}$ Department of Pharmacy, China-USA Lipids in Health and Disease Research Center; ${ }^{6}$ Department of Pharmacy, \\ Guangxi Key Laboratory of Molecular Medicine in Liver Injury and Repair; ${ }^{7}$ Department of Pharmacy, \\ Guangxi Key Laboratory of Sphingolipid Metabolism (Incubated), Guilin Medical University, \\ Guilin, Guangxi Zhuang Autonomous Region 541001, P.R. China
}

Received July 28, 2020; Accepted January 13, 2021

DOI: $10.3892 / \mathrm{ol} .2021 .12560$

\begin{abstract}
MicroRNA-30a-5p (miR-30a-5p), which functions as a tumor suppressor, has been reported to be downregulated in colorectal cancer (CRC) tissues and to be associated with cancer invasion. However, the detailed regulatory mechanism of curcumol in the malignant progression of CRC remains unknown. MTT, Transwell, scratch, western blotting and reverse transcription-quantitative PCR assays were performed to examine how curcumol inhibited CRC cell viability, invasion and migration, and to detect the role of miR-30a-5p and curcumol in the invasion and Hippo signaling pathways of CRC cells. The present study revealed that miR-30a-5p expression was downregulated in human CRC tissues and cells. The results demonstrated that miR-30a-5p downregulation was accompanied by the inactivation of the Hippo signaling pathway, which was demonstrated to promote CRC cell viability, invasion and migration. Curcumol treatment was identified to increase miR-30a-5p expression and to activate the Hippo signaling pathway, which in turn inhibited the invasion and migration of CRC cells. Overexpression of miR-30a-5p enhanced the effects of curcumol on cell invasion
\end{abstract}

Correspondence to: Miss Juan Wang or Professor Xu Chen, Department of Pharmacy, Guilin Medical University, 1 Zhiyuan Road, Lingui, Guilin, Guangxi Zhuang Autonomous Region 541001, P.R. China

E-mail: juanlovelife@163.com

E-mail: chenxu@glmc.edu.cn

${ }^{*}$ Contributed equally

Key words: curcumol, colorectal cancer, microRNA-30a-5p, viability, invasion, Hippo and migration, and the Hippo signaling pathway in CRC cells. Furthermore, downregulation of miR-30a-5p reversed the effects of curcumol on cell invasion and migration, and the Hippo signaling pathway in CRC cells. These findings identified novel signaling pathways associated with miR-30a-5p and revealed the effects of curcumol on miR-30a-5p expression. Therefore, curcumol may serve as a potential therapeutic strategy to delay CRC progression.

\section{Introduction}

Colorectal cancer (CRC) is a common gastrointestinal tumor in China (1). CRC was the third most widely diagnosed cancer and had the second highest mortality among cancer types worldwide in 2018 (2). Low survival rates, poor surgical prognosis and the emergence of drug resistance have resulted in unsatisfactory clinical outcomes. The invasion of CRC is one of the main reasons for its high mortality and poor prognosis (3). Furthermore, $29 \%$ of CRC-associated deaths are associated with distant invasion (4). There is no specific treatment to restrain the invasion, which indicates the importance of identifying novel molecular mechanisms driving these processes. Therefore, identifying novel therapeutic strategies and novel target molecules for the invasion of CRC remains important.

MicroRNAs (miRNAs/miRs) are a class of non-coding single-stranded small-molecule RNAs that degrade target gene expression via binding to the 3'-untranslated region. It has been reported that numerous miRNAs, including the miR-30 family, serve important roles in the regulation of cancer cell migration and invasion (5-7). It has been reported that miR-30a-5p expression is decreased in primary gallbladder cancer (GBC) lesions, and inhibition of its expression in GBC cells promoted migration and invasion (8). Wang et al (9) reported that miR-30a-5p upregulation can inhibit ovarian cancer epithelial-mesenchymal transition (EMT) and invasion. 
In addition, miR-30a-5p expression is downregulated in CRC lesions and suppresses CRC invasion via the inhibition of integrin $\beta$-3 (ITGB3) (10), suggesting that miR-30a-5p may be a promising target for the treatment of CRC.

Yes-associated protein (YAP), which is a crucial downstream effector of the Hippo signaling pathway, has also been demonstrated to be involved in the EMT process $(11,12)$. Furthermore, it has been demonstrated that dysregulation of the Hippo-YAP signaling pathway is associated with EMT and cancer progression mainly driven by YAP $(12,13)$. Therefore, YAP-mediated EMT is considered to be a critical therapeutic target to inhibit YAP-promoted tumor invasion, and YAP may be a promising target for the treatment of CRC.

Curcumol is extracted from the traditional Chinese medicine Rhizoma curcumae, which has been reported to possess multiple pharmacological bioactivities, including antioxidant, anti-inflammatory, antifibrosis, antimicrobial and antitumor activities (14-16). It has been demonstrated that curcumol exerts antitumor effects against multiple types of cancer, including gastric cancer (17), cholangiocarcinoma (18), nasopharyngeal carcinoma (19) and colorectal carcinoma (20). Our previous studies revealed that curcumol inhibits CRC cell proliferation and induces apoptosis via the p38 MAPK and PI3K/Akt signaling pathways $(21,22)$. However, to the best of our knowledge, the specific mechanism of curcumol-inhibited CRC cell invasion has not been clearly elucidated. The present study examined the effects of curcumol on miR-30a-5p and the YAP signaling pathway, and revealed its possible mechanisms of CRC cell invasion inhibition.

\section{Materials and methods}

Reagents and cell lines. RPMI-1640, DMEM, Opti-MEM I Reduced Serum medium and FBS were purchased from Gibco; Thermo Fisher Scientific, Inc. MTT and DMSO were purchased from Amresco, LLC. All-in-One miRNA Detection kit was purchased from GeneCopoeia, Inc. TRNzol Universal RNA Reagent was purchased from Tiangen Biotech Co. Ltd. GoScript ${ }^{\mathrm{TM}}$ Reverse Transcriptase was purchased from Promega Corporation. UltraSYBR Mixture was purchased from Jiangsu Kangwei Century Biotechnology Co., Ltd. Lipofectamine $^{\mathrm{TM}} 3000$ transfection reagent was purchased from Invitrogen; Thermo Fisher Scientific, Inc. pPLK/GFP+ Puro-hsa-miR-30a-5p sponge (miR-30a-5p-sp) and its negative control (NC) were purchased from Yipu Biotechnology. Hsa-miR-30a-5p-mimic and its NC were purchased from Shanghai Integrated Biotech Solutions Co., Ltd. SW480 human CRC cell lines were obtained from Xiangya Medical College of Central South University (Changsha, China) and stored at our laboratory (Key Laboratory of Pharmacognosy, Guilin Medical University, Guilin, China). The HCT116 and SW620 human CRC cell lines were purchased from American Type Culture Collection. The HCoEpiC human normal colorectal cell line was purchased from Jennio Biotech Co., Ltd..

Study samples. CRC tissues and matched tumor-adjacent tissues were obtained from patients with $\mathrm{CRC}$ at the First Affiliated Hospital of Guilin Medical College (Guilin, China). These samples were collected between February 2016 and August 2016. The age under 49 years old (17.65\%), the age between 50-69 years old (66.17\%), the age over 70 years old (16.18\%). There were $36.76 \%$ male patients and $63.24 \%$ female patients. The inclusion criteria was that patients diagnosed with colon cancer. The inclusion criteria was that patients without drug intervention. The corresponding adjacent tissues were obtained $\geq 2 \mathrm{~cm}$ apart from the cancerous node. It was determined that the patients did not receive any preoperative treatment. All tissues were quickly frozen in liquid nitrogen and stored at $-80^{\circ} \mathrm{C}$ until use. All samples were studied with the written consent of the patient and approval from Guilin Medical College Ethics Committee (Guilin, China).

Xenograft assays. BALB/c athymic nude mice (male; weight, $\sim 20 \mathrm{~g} ; \mathrm{n}=10$ mice) were purchased from Shanghai SLAC Laboratory Animal Co., Ltd, and were housed under standard laboratory conditions. HCT116 cells $\left(1 \times 10^{7}\right)$ suspended in $200 \mu 1$ sterile PBS were injected subcutaneously into the right flank of 5-week-old BALB/c nude mice. After 2 weeks, when the tumor size reached $\sim 100 \mathrm{~mm}^{3}$, the mice were randomly divided into two groups (5 mice in each group). Curcumol was dissolved in $90 \%$ propylene glycol, and the mode of administration was intragastric. The maximal tumor volume allowed in in vivo experiments was $\sim 900 \mathrm{~mm}^{3}$. The room temperature was $26-28^{\circ} \mathrm{C}$, the relative humidity was maintained at 40-60\% and a 14-h light/10-h dark cycle was used. The food and drinking water required by nude mice was autoclaved $\left(45 \mathrm{~min} ; 120^{\circ} \mathrm{C}\right)$. Commercial mice diet-pellets and water were available to mice ad libitum. After 3 weeks of treatment, mice were sacrificed by cervical dislocation at room temperature. The time interval between injection and final tumor growth measurement and/or the end of the experiment was 5 weeks. The dose of sodium pentobarbital anesthesia was calculated according to body weight. All operations were performed under sodium pentobarbital anesthesia and intraperitoneal administration was selected. All efforts were made to minimize suffering. The tumor issues were collected in a $1.5 \mathrm{ml}$ Eppendorf tube and stored at $-80^{\circ} \mathrm{C}$ until further use. The present study was approved by the Committee on the Ethics of Animal Experiments of Guilin Medical College (Guilin, China).

Curcumol preparation. Curcumol was purchased from Guizhou Dida Technology Co., Ltd.. The storage solution of curcumol was prepared as $20 \mathrm{mg}$ curcumol dissolved in $1 \mathrm{ml}$ anhydrous ethanol as the original solution, and this was then diluted to the desired concentration. Curcumol solution was stored at $-4^{\circ} \mathrm{C}$.

Cell culture. Human CRC cell lines (HCT116, SW480 and SW620) were cultured in RPMI-1640 medium with 10\% FBS, $100 \mathrm{U} / \mathrm{ml}$ penicillin and streptomycin. The HCoEpiC human normal colorectal cell line was cultured in MEM with $10 \%$ FBS, $100 \mathrm{U} / \mathrm{ml}$ penicillin and streptomycin. The cells were washed with $1 \mathrm{X}$ PBS and digested with $0.25 \%$ trypsin. The cells were cultured in an incubator at $37^{\circ} \mathrm{C}$ with $5 \% \mathrm{CO}_{2}$. The cells were routinely passaged 3-4 times a week, and after cells were completely adherent to the dishes, cells were treated with curcumol for $48 \mathrm{~h}$ in an incubator at $37^{\circ} \mathrm{C}$ with $5 \% \mathrm{CO}_{2}$ for subsequent experiments. The remaining cell lines were stored at $-80^{\circ} \mathrm{C}$. 
Table I. Sequences of forward and reverse primers used in reverse transcription-quantitative PCR.

\begin{tabular}{ll}
\hline Gene & \multicolumn{1}{c}{ Sequences (5'-3') } \\
\hline E-cadherin & F: CACCCGGGACAACGTTTATTA \\
R: AGCTGGCTCAAGTCAAAGTC \\
F-catenin & R: CTGCCAAGTGGGTGGTATAG \\
MMP2 & F: GGCACCCATTTACACCTACA \\
& R: CCAAGGTCAATGTCAGGAGAG \\
LATS1 & F: ATCTCCCGAATCTCTCCTGT \\
& R: AATGCCTCTCTGTCCTTGATTAG \\
MST-1 & F: GAGACCAAAGGTACGGGTAATG \\
& R: GTCCTCGGTGCTTGATGTT \\
YAP1 & F: AGCATCTTCGACAGTCTTCTTT \\
& R: GTTGTTGTCTGATCGATGTGATTT \\
GAPDH & F: TGCACCACCAACTGCTTAGC \\
& R: GGCATGGACTGTGGTCATGAG
\end{tabular}

YAP1, Yes-associated protein; MST-1, mammalian STE20-like protein kinase; LATS1, large tumor suppressor kinase 1; F, forward, $\mathrm{R}$, reverse.

Plasmid construction, stable transfection and cell transfection. miR-30a-5p-sp and its NC were purchased from Yipu Biotechnology. miR-30a-5p-sp (1.215 $\mu \mathrm{g})$ plasmid was used to knock down the expression of miR-30a-5p, and miR-30a-5p-sp is an inhibitor of miR-30a-5p. miR-30a-5p-sp (1.215 $\mu \mathrm{g})$ plasmid was transfected into HCT116 cells, and the duration of transfection was $48 \mathrm{~h}$. Subsequently, $1 \times 10^{7}$ HCT1116 cells transfected with miR-30a-5p sponge or NC were collected. The multiplicity of infection used to infect cells was 5. miR-30a-5p mimic was used to overexpress miR-30a-5p. miR-30a-5p-sp plasmid (50 $\mathrm{ng} / \mu \mathrm{l})$ was amplified using the endotoxin-free medium extraction kit, and agarose gel electrophoresis (1\%) was used to detect miR-30a-5p amplification. The amplified plasmids were packaged into $293 \mathrm{~T}$ cells (American Type Culture Collection) using Lipofectamine ${ }^{\circledR} 3000(7.5 \mu \mathrm{l})$ and $\mathrm{P} 3000(5 \mu \mathrm{l})$ reagents at $37^{\circ} \mathrm{C}$ with $5 \% \mathrm{CO}_{2}$. A second generation lentivirus packaging system was used. The ratio of PMD2.G:PSPAx2:miR-30a-5p-sp or NC (1.215 $\mu \mathrm{g})$ was 1:2:2. The liquid was changed $6 \mathrm{~h}$ later. The supernatant was collected after $24 \mathrm{~h}$. The supernatant was obtained by centrifugation, and the centrifugation conditions were $2,500 \mathrm{x} \mathrm{g}$ for $3 \mathrm{~min}$ at room temperature. The 293 T cells were cultured in DMEM with $10 \%$ FBS and $100 \mathrm{U} / \mathrm{ml}$ penicillin and streptomycin. The cells were washed with $1 \mathrm{X}$ PBS and digested with $0.25 \%$ trypsin. The cells were cultured in an incubator at $37^{\circ} \mathrm{C}$ with $5 \% \mathrm{CO}_{2}$. The cells were routinely passaged 3-4 times a week. HCT116 cells were transfected with miR-30a-5p-sp for $5 \mathrm{~h}$ and subsequently placed in fresh medium for $12 \mathrm{~h}$ at $37^{\circ} \mathrm{C}$ with $5 \% \mathrm{CO}_{2}$. The fluorescence of miR-30a-5p-sp and its NC was observed following transfection for $24 \mathrm{~h}$ to confirm successful transfection. The sequence of short hairpin RNA targeting miR-30a-5p-sp was as follows: 5'-CTTCCAGTCGCCTTGTTTACA-3'. Empty vector (miR-30a-5p-sp-NC) was transfected into HCT116 cells, in which no gene sequence was inserted. miR-30a-5p mimic $(20 \mu \mathrm{M})$ was transfected into HCT116 cells using Lipofectamine $^{\circledR} 3000$ reagent. The duration of transfection was $48 \mathrm{~h}$. The miR-30a-5p mimic sequence was as follows: Sense, 5'-UGUAAACAUCCUCGACUGGAAG-3' and anti-sense, 5'-CUUCCAGUCGAGGAUGUUUACA-3'. The mimics NC sequence was as follows: Sense, 5'-UCACAACCUCCUAGA AAGAGUAGA-3' and anti-sense, 5'-UACUCUUUCUAGGAG GUUGUGAUU-3'. The cells were cultured for another $48 \mathrm{~h}$ and harvested for subsequent experiments.

MTT analysis. HCT116 cells were cultured in 96-well plates at a density of $3 \times 10^{3}$ cells/well and treated with various concentrations of curcumol $(0,10,20,40,80,100,120$ and $160 \mu \mathrm{g} / \mathrm{ml})$ at $37^{\circ} \mathrm{C}$. After 24,48 and $72 \mathrm{~h}, 20 \mu \mathrm{l} \mathrm{MTT}$ solution was added, and the cells were cultured for another $4 \mathrm{~h}$ in an incubator at $37^{\circ} \mathrm{C}$ with $5 \% \mathrm{CO}_{2}$. A total of $150 \mu \mathrm{l}$ DMSO was added once the cell suspension was removed. The absorbance values were measured at a wavelength of $490 \mathrm{~nm}$ using a microplate reader. The optical density values were used to calculate the $\mathrm{IC}_{50}$. The experiment was performed in triplicate.

$R N A$ extraction and reverse transcription-quantitative $P C R$ (RT-qPCR). Total RNA was extracted from tissues and cells using TRNzol Universal RNA Reagent (Tiangen Biotech Co., Ltd.) according to the manufacturer's protocol. The 260/280 values ranged between 1.8 and 2.2. A total of $2 \mu \mathrm{g}$ total RNA was reverse transcribed into cDNA using a GoScript ${ }^{\mathrm{TM}}$ Reverse Transcription Mix at $42^{\circ} \mathrm{C}$ for $20 \mathrm{~min}$ and $90^{\circ} \mathrm{C}$ for $5 \mathrm{~min}$. The fluorophore was SYBR Green (CoWin Biosciences). The thermocycling conditions were as follows: $95^{\circ} \mathrm{C}$ for $30 \mathrm{sec}$, 40 cycles of $95^{\circ} \mathrm{C}$ for $5 \mathrm{sec}$ and $60^{\circ} \mathrm{C}$ for $30 \mathrm{sec}$, followed by $95^{\circ} \mathrm{C}$ for $15 \mathrm{sec}, 60^{\circ} \mathrm{C}$ for $1 \mathrm{~min}, 95^{\circ} \mathrm{C}$ for $15 \mathrm{sec}$ and $50^{\circ} \mathrm{C}$ for $30 \mathrm{sec}$. This protocol was used for E-cadherin, $\beta$-catenin, MMP2, LATS1, MST-1, YAP1 and GAPDH. The primers were purchased from Invitrogen; Thermo Fisher Scientific, Inc.). The primer sequences are presented in Table I. A total of $2 \mu \mathrm{g}$ total RNA was reverse transcribed using the All-in-One miRNA Detection kit at $37^{\circ} \mathrm{C}$ for $1 \mathrm{~h}$ and $85^{\circ} \mathrm{C}$ for $5 \mathrm{~min}$, and the thermocycling conditions were as follows: $95^{\circ} \mathrm{C}$ for $10 \mathrm{~min}$, followed by 40 cycles of $95^{\circ} \mathrm{C}$ for $10 \mathrm{sec}$ and $60^{\circ} \mathrm{C}$ for $1 \mathrm{~min}$. This protocol was used for miR-30a-5p. RT-qPCR was performed using the Applied Biosystems 7500 Fast RT-PCR system (Applied Biosystems; Thermo Fisher Scientific, Inc.). U6 was used as the internal control to normalize miR-30a-5p expression. The sequences of the U6 primers were as follows: Forward, 5'-GCTTCGGCAGCACATATACTAAAAT-3' and reverse, 5'-CGCTTCACGAATTTGCGTGTCAT-3'. The hsa-miR-30a-5p primer was purchased from GeneCopoeia, Inc. The relative expression levels of miR-30a-5p were calculated using the $2^{-\Delta \Delta \mathrm{Cq}}$ method (23). The experiments were performed in biological triplicates.

Western blotting. Protein was extracted from tissues/cells using RIPA lysis buffer (Beijing Solarbio Science \& Technology Co., Ltd.) containing $2 \mu \mathrm{g} / \mathrm{ml}$ aprotinin, $5 \mu \mathrm{g} / \mathrm{ml}$ leupeptin, $1 \mu \mathrm{g} / \mathrm{ml}$ pepstatin, $1 \mathrm{~mol} / \mathrm{l}$ dithiothreitol and $1 \mathrm{~mol} / \mathrm{l} \mathrm{PMSF}$. The lysates were centrifuged at $13,400 \mathrm{x}$ g for $20 \mathrm{~min}$ at $4^{\circ} \mathrm{C}$. Protein concentrations were determined using a BCA assay. Proteins 

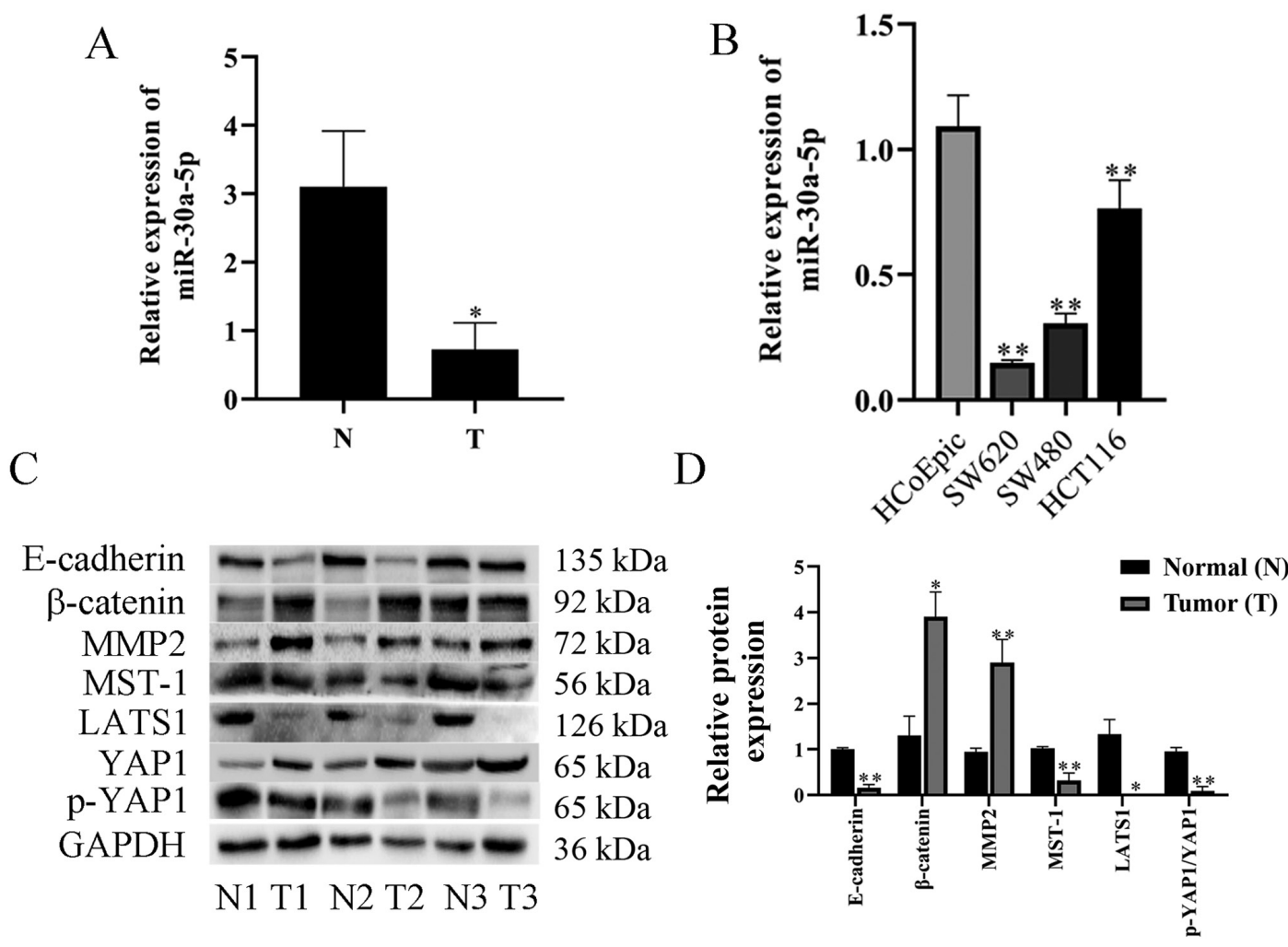

Figure 1. miR-30a-5p expression and Hippo signaling pathway activity in CRC tissue samples. miR-30a-5p expression in (A) six pairs of CRC and paracancerous tissues, and (B) CRC cell lines was analyzed by RT-qPCR. (C) Expression levels of epithelial-mesenchymal transition, MMP2 and Hippo signaling pathway-associated proteins in three pairs of CRC and paracancerous tissues were analyzed by western blotting. (D) Semi-quantitative analysis of the results of western blotting. RT-qPCR and western blotting data are presented as the mean \pm standard deviation of three independent experiments. ${ }^{*} \mathrm{P}<0.05$ and ${ }^{* *} \mathrm{P}<0.01$ vs. control (normal or HCoEpic). miR, microRNA; RT-qPCR, reverse transcription-quantitative PCR; CRC, colorectal cancer; MST-1, mammalian STE20-like protein kinase; LATS1, large tumor suppressor kinase 1; YAP1, Yes-associated protein; p, phosphorylated; N, normal tissue; T, tumor tissue.

(30 $\mu \mathrm{g} /$ lane) of different molecular weights were separated using $10 \%$ SDS-PAGE. Protein was then transferred to PVDF membranes. The membranes were incubated with $5 \%$ skim milk for $2 \mathrm{~h}$ at room temperature. Membranes were incubated with primary antibodies against large tumor suppressor kinase 1 (LATS1; dilution, 1:1,000; cat. no. ab243656; Abcam), YAP1 and phosphorylated (p)-YAP1 (dilution, 1:1,000; cat. nos. ab52771 and ab76252; Abcam), E-cadherin (dilution, 1:2,000; cat. no. \#3195; Cell Signaling Technology, Inc.), $\beta$-catenin (dilution, 1:2,000; cat. no. \#8480; Cell Signaling Technology, Inc.), mammalian STE20-like protein kinase (MST-1; dilution, 1:2,000; cat. no. \#DF7691; Affinity Biosciences), MMP2 (dilution, 1:1,000; cat. no. 10373-2-AP; ProteinTech Group, Inc.) and GAPDH (dilution, 1:2,000; cat. no. TA-08; OriGene Technologies, Inc.) overnight at $4^{\circ} \mathrm{C}$, followed by incubation with horseradish peroxidase-labeled anti-mouse (dilution, 1:4,000; cat. no. EM35110-01; Beijing Emarbio Science \& Technology Co., Ltd.) or anti-rabbit secondary antibodies (dilution, 1:4,000; cat. no. 31460; Thermo Fisher Scientific, Inc.) for $1 \mathrm{~h}$ at $37^{\circ} \mathrm{C}$. Protein signals were detected with an enhanced chemiluminescence reagent (Bio-Rad Laboratories, Inc.) on the ChemiDoc XRS+ instrument (Bio-Rad Laboratories, Inc.). The results were measured using Gel-pro Analyzer 32 software (version 4.0; Media Cybernetics, Inc.).

Transwell assay. Matrigel matrix (BD Biosciences) was melted in a $4^{\circ} \mathrm{C}$ refrigerator in advance, and diluted in RPMI- 1640 medium at a ratio of 1:6. A total of $50 \mu 1$ matrix was added to the upper Transwell chamber of 24-well transwell chamber inserts (BD Biosciences) at $37^{\circ} \mathrm{C}$ for $4 \mathrm{~h}$. HCT116 cell density was adjusted to $3 \times 10^{5}$ per $200 \mu 1$ RPMI- 1640 medium and plated in the upper chamber at $37^{\circ} \mathrm{C}$ with $5 \% \mathrm{CO}_{2}$ for $48 \mathrm{~h}$. A total of $600 \mu \mathrm{l}$ RPMI-1640 medium supplemented with $10 \%$ FBS was plated in lower chamber at $37^{\circ} \mathrm{C}$ with $5 \% \mathrm{CO}_{2}$. After $48 \mathrm{~h}$, the Matrigel matrix was removed and fixed in $4 \%$ paraformaldehyde for $30 \mathrm{~min}$ at room temperature, and stained with $0.1 \%$ crystal violet at $37^{\circ} \mathrm{C}$ for $20 \mathrm{~min}$. PBS was used to wash the Transwell chamber. Subsequently, cell invasion was observed under a light microscope (magnification, x100). Invasion of cells at $48 \mathrm{~h}$ was calculated using ImageJ1.50i software (National Institutes of Health) using the following formula: Relative invasion rate $(\%)=\left(\right.$ cell penetration $\left./ 3 \times 10^{5}\right)$ $x 100$. Three independent experiments were performed, and the data are presented as the mean $\pm \mathrm{SD}$.

Scratch assay. Curcumol-treated HCT116 cells were inoculated in a six-well plate. The cells were serum-starved for this assay to avoid the effects of cell viability. When the cells had grown to fuse into a monolayer, the cells were scratched with a 200- $\mu 1$ pipette tip perpendicular to the bottom of the well and washed with PBS twice to remove the remaining cells. HCT116 cells were cultured in RPMI- 1640 medium at $37^{\circ} \mathrm{C}$ with curcumol for $48 \mathrm{~h}$. Images were captured at 0,24 and $48 \mathrm{~h}$, where $0 \mathrm{~h}$ was recorded as the starting time point. The 
A

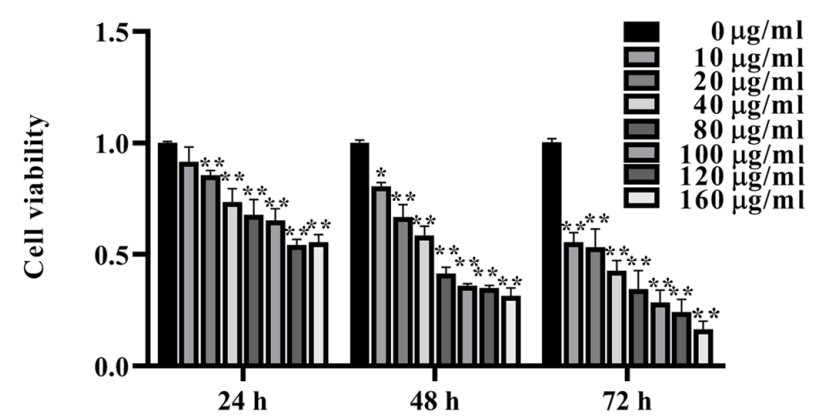

C
$0 \mathrm{~h}$

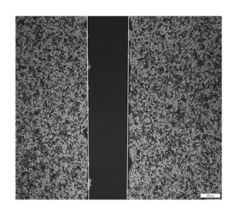

$24 \mathrm{~h}$

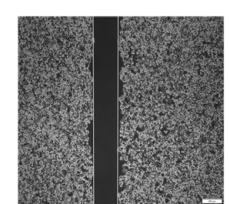

$48 \mathrm{~h}$

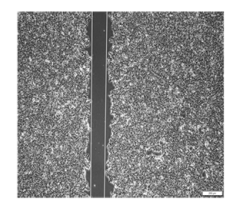

$\mathbf{0}$

E

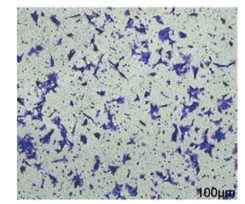

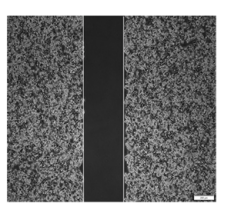
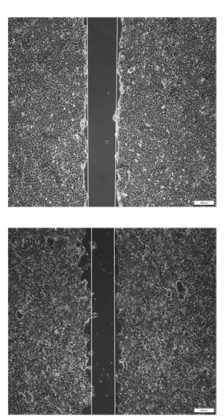

50

Curcumol $(\mu \mathrm{g} / \mathrm{ml})$

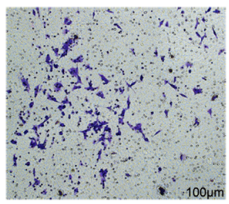

50

Curcumol ( $\mu \mathrm{g} / \mathrm{ml})$

G

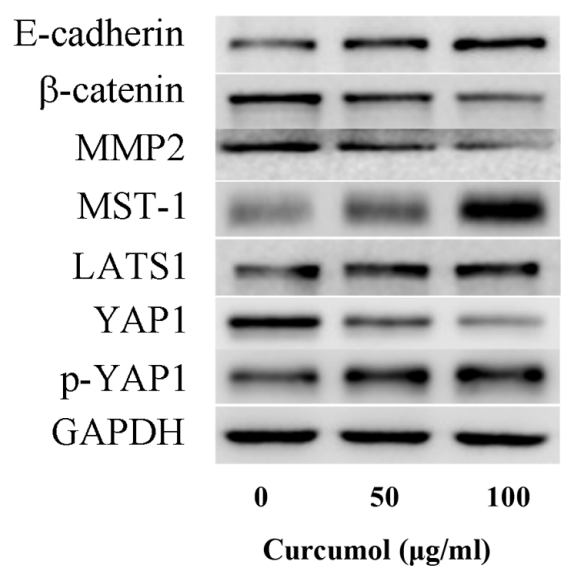

B
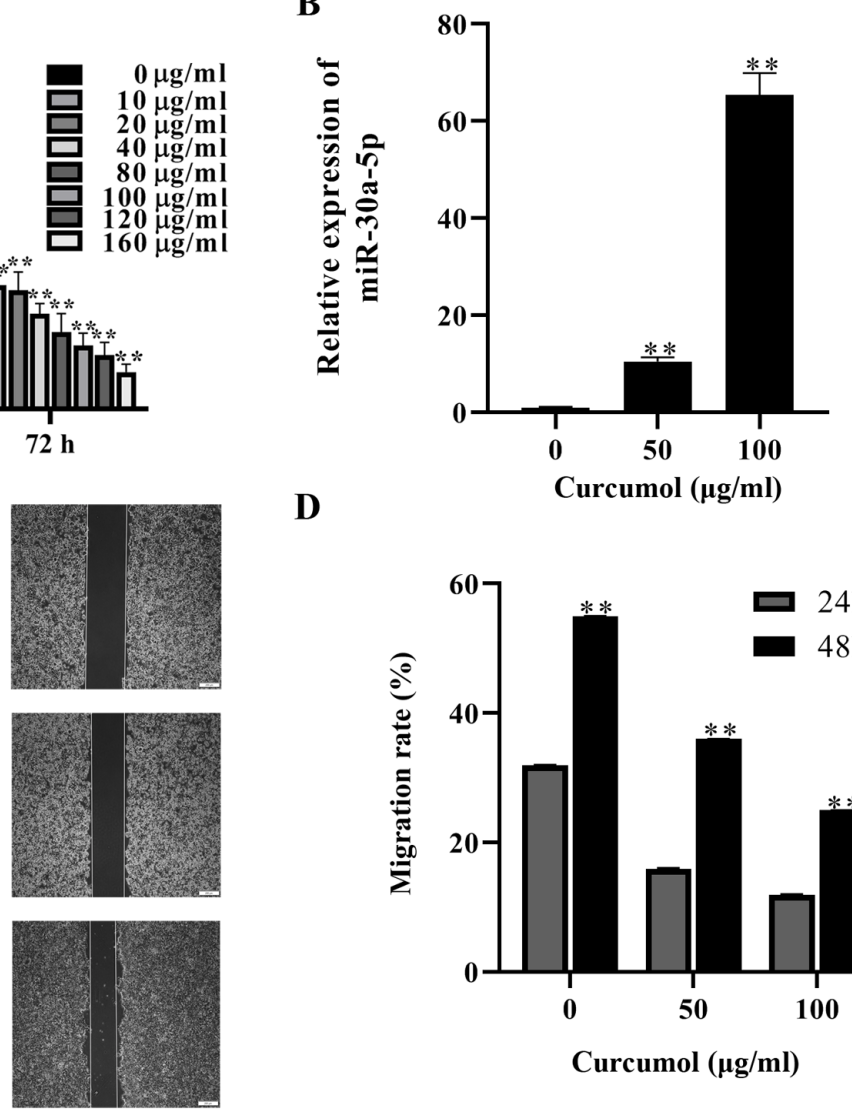

100

F
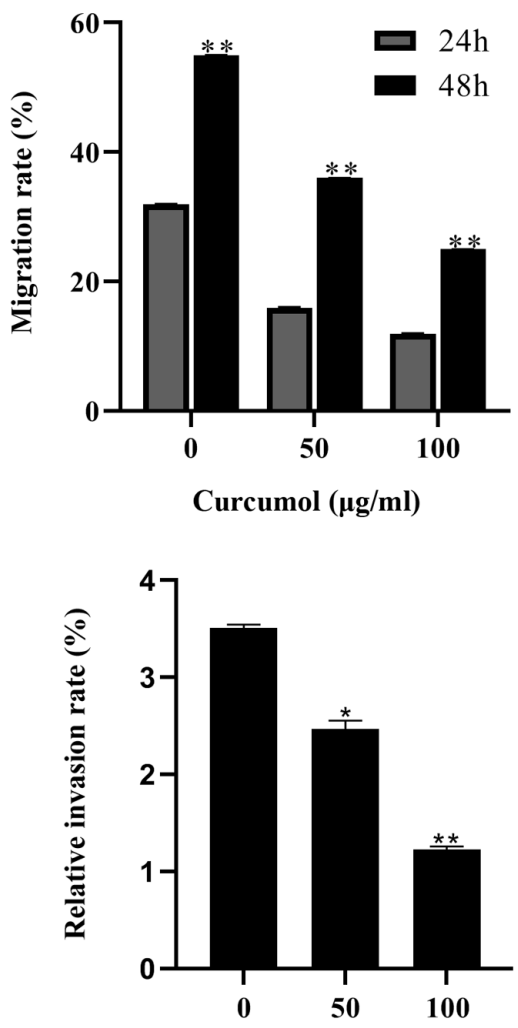

Curcumol ( $\mu \mathrm{g} / \mathrm{ml})$

H
$135 \mathrm{KDa}$

$92 \mathrm{KDa}$

$72 \mathrm{KDa}$

$56 \mathrm{KDa}$

$126 \mathrm{KDa}$

$65 \mathrm{KDa}$

$65 \mathrm{KDa}$

$36 \mathrm{KDa}$

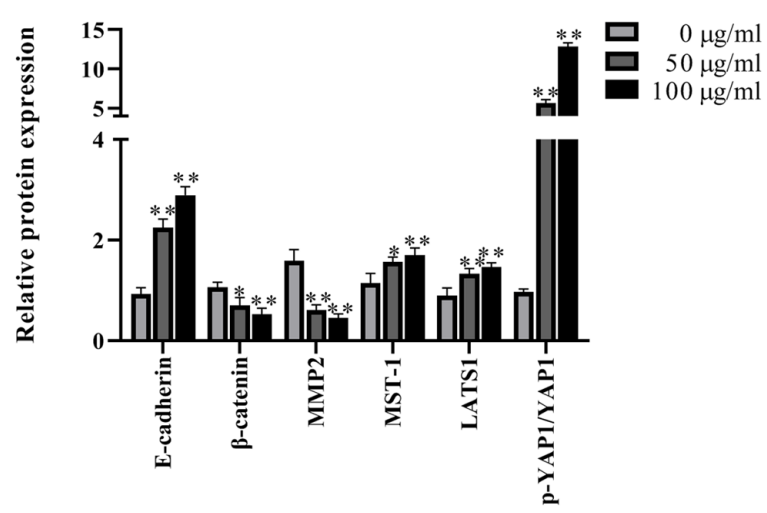

Figure 2. Curcumol inhibits viability, invasion and migration by targeting miR-30a-5p. (A) Curcumol inhibited HCT116 cell viability. (B) Reverse transcription-quantitative PCR was performed and revealed that miR-30a-5p expression was increased by curcumol treatment. (C) Scratch experiments revealed that curcumol inhibited the migration of HCT116 cells (magnification, x40). (D) Quantitative histogram of the results of the scratch experiments. (E) Transwell experiments revealed that curcumol inhibited the invasion of HCT116 cells (magnification, x100). (F) Quantitative histogram of the results of the Transwell experiments. (G) Expression levels of YAP1, $\beta$-catenin, MMP2, E-cadherin, MST-1, LATS1 and p-YAP1 were regulated by curcumol in HCT116 cells. (H) Semi-quantitative analysis of the results of western blotting. ${ }^{*} \mathrm{P}<0.05$ and ${ }^{* *} \mathrm{P}<0.01$ vs. control (no curcumol group). miR, microRNA; YAP1, Yes-associated protein; MST-1, mammalian STE20-like protein kinase; LATS1, large tumor suppressor kinase 1; p, phosphorylated. 
width of the scratch was observed and recorded under a light microscope (magnification, $\mathrm{x} 40$ ). The image was processed using ImageJ1.50i software (National Institutes of Health) and the proportion of relative wound closure was calculated. The following formula was used: Change rate of scratch area $(\%)=(0 \mathrm{~h}$ scratch area- $24 \mathrm{~h}$ scratch area $) / 0 \mathrm{~h}$ scratch area $\mathrm{x} 100$.

Statistical analysis. All statistical analyses were performed using SPSS Statistics 22 software (IBM Corp.). Data are presented as the mean \pm SD. The unpaired t-test was used to analyze two independent groups. The paired t-test was used to analyze the data in Fig. 1A and D. One-way ANOVA followed by Bonferroni and LSD was used to assess statistical significance for multiple comparisons. All experiments were repeated in triplicate. $\mathrm{P}<0.05$ was considered to indicate a statistically significant difference.

\section{Results}

miR-30a-5p expression and activation of the Hippo signaling pathway in CRC tissue samples. Six pairs of CRC tissues and paracancerous tissues were collected from the First Affiliated Hospital of Guilin Medical College. miR-30a-5p expression in CRC tissues and adjacent tissues that were collected clinically was detected by RT-qPCR. The present study used a paired t-test to analyze two groups. miR-30a-5p expression was lower in CRC tissues compared with in paracancerous tissues (Fig. 1A). Subsequently, miR-30a-5p expression was examined in HCoEpic, HCT116, SW480 and SW620 cells. miR-30a-5p expression in HCoEpic cells was the highest among these cell lines. miR-30a-5p expression was second highest in HCT116 cells (Fig. 1B). Additionally, the study used a paired t-test to compare the CRC tissues group and the adjacent tissues group. The expression levels of $\beta$-catenin and MMP2 were increased, whereas the expression levels of E-cadherin were decreased in the tumor tissues. The expression levels of MST-1, LATS1 and p-YAP1, which are key factors of the Hippo signaling pathway, were decreased in CRC tissues, while YAP1 expression was increased according to western blot analysis (Fig. 1C and D).

Curcumol inhibits HCT116 cell viability and invasion. The MTT assay demonstrated that curcumol inhibited the viability of HCT116 cells in a dose- and time-dependent manner (Fig. 2A), as previously reported (21). miR-30a-5p expression was upregulated as curcumol concentration increased (Fig. 2B). Following treatment of HCT116 cells with curcumol $(0,50$ and $100 \mu \mathrm{g} / \mathrm{ml}$ ) for 0,24 and $48 \mathrm{~h}$, Scratch assays revealed that with the increase of curcumol concentration, the migration ability of HCT116 cells was inhibited, and the cells exhibited a significant difference at $48 \mathrm{~h}$ compared with $24 \mathrm{~h}$ (Fig. 2C and D). Transwell assays revealed that with the increase in curcumol concentration, the invasion ability of HCT116 cells was inhibited (Fig. 2E and F). Western blotting demonstrated that YAP1, $\beta$-catenin and MMP2 expression was inhibited by curcumol, while the expression levels of E-cadherin, MST-1, LATS1 and p-YAP1 in HCT116 cells were increased following curcumol treatment (Fig. $2 \mathrm{G}$ and H). Therefore, these data suggested that curcumol inhibited HCT116 cell viability, invasion and migration, upregulated miR-30a-5p expression and activated the Hippo signaling pathway.

Effects of miR-30a-5p on CRC cell invasion and the Hippo signaling pathway in CRC cells. To further determine the effects of miR-30a-5p on CRC cell invasion and the association with the Hippo signaling pathway, HCT116 cells were transfected with miR-30a-5p-sp and miR-30a-5p mimics. The MTT assay demonstrated that miR-30a-5p-sp promoted HCT116 cell viability, while miR-30a-5p mimics inhibited their viability (Fig. 3A). RT-qPCR demonstrated that miR-30a-5p-sp and mimics were successfully transfected into HCT116 cells (Fig. 3B). Scratch assays revealed that miR-30a-5p-sp promoted HCT116 cell migration, while miR-30a-5p mimics inhibited their migration, and there was a significant difference at $48 \mathrm{~h}$ compared with $24 \mathrm{~h}$ (Fig. 3C and D). Transwell assay demonstrated that miR-30a-5p-sp promoted HCT116 cells invasion, while miR-30a-5p mimics inhibited their invasion (Fig. 3E and F). When miR-30a-5p-sp was transfected into HCT116 cells, the expression levels of YAP1, $\beta$-catenin and MMP2 were increased, and the expression levels of E-cadherin, MST-1, LATS1 and p-YAP1 were decreased. However, when the expression levels of miR-30a-5p were upregulated, YAP1, $\beta$-catenin and MMP2 expression was decreased, and the expression levels of E-cadherin, MST-1, LATS1 and p-YAP1 were increased in HCT116 cells transfected with miR-30a-5p mimics (Fig. 3G and $\mathrm{H}$ ).

miR-30a-5p overexpression enhances the inhibitory effects of curcumol on invasion and the Hippo signaling pathway in HCT116 cells. To investigate the association between curcumol and miR-30a-5p, the present study first overexpressed miR-30a-5p and then analyzed the inhibitory effect of curcumol on invasion and migration in HCT116 cells. MTT assays demonstrated that miR-30a-5p mimics and curcumol $(50 \mu \mathrm{g} / \mathrm{ml})$ inhibited HCT116 cell viability. Following treatment with both miR-30a-5p mimics and curcumol simultaneously, HCT116 cell viability was significantly inhibited compared with treatment with miR-30a-5p mimics alone (Fig. 4A). RT-qPCR revealed that miR-30a-5p expression was upregulated after treatment with miR-30a-5p mimics or curcumol alone. The expression levels of miR-30a-5p were higher following treatment with both miR-30a-5p mimics and curcumol (Fig. 4B). Scratch assays demonstrated that miR-30a-5p mimics and curcumol $(50 \mu \mathrm{g} / \mathrm{ml})$ inhibited HCT116 cell migration, following treatment with both miR-30a-5p mimics and curcumol simultaneously, HCT116 cell migration was more inhibited compared with miR-30a-5p mimics and curcumol $(50 \mu \mathrm{g} / \mathrm{ml})$ alone, and HCT116 cell migration was increased at $48 \mathrm{~h}$ compared with $24 \mathrm{~h}$ (Fig. 4C and D). Transwell assays demonstrated that miR-30a-5p mimics and curcumol $(50 \mu \mathrm{g} / \mathrm{ml})$ inhibited HCT116 cell invasion. Following treatment with both miR-30a-5p mimics and curcumol simultaneously, HCT116 cell invasion was significantly inhibited compared with that of cells treated with miR-30a-5p mimics alone (Fig. 4E and F). Western blotting demonstrated that when miR-30a-5p mimics were transfected into HCT116 cells, the expression levels of YAP1, $\beta$-catenin and MMP2 were decreased, and the levels of E-cadherin, MST-1, LATS1 and p-YAP1 were increased. miR-30a-5p mimics increased the inhibitory effect of curcumol 
A

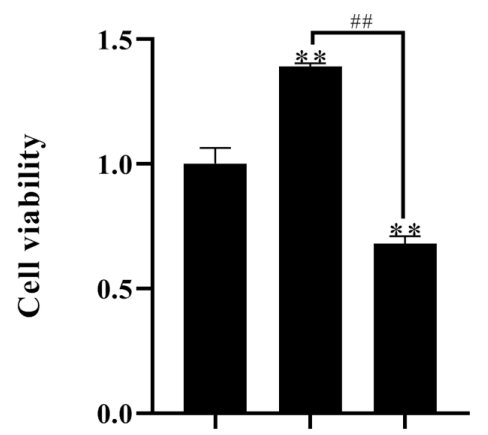

miR-30a-5p-sp miR-30a-5p mimics

C

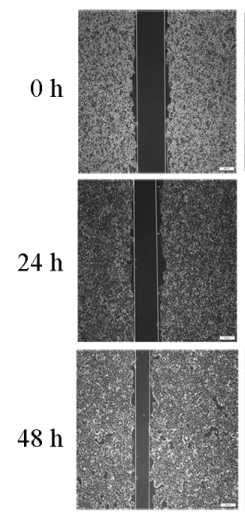

$\mathrm{miR}-30 \mathrm{a}-5 \mathrm{p}-\mathrm{sp}-$ miR-30a-5p mimics -

E
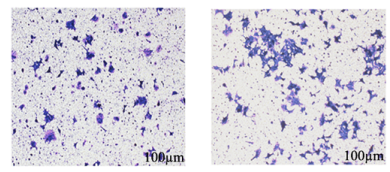

miR-30a-5p-sp

miR-30a-5p mimics

G

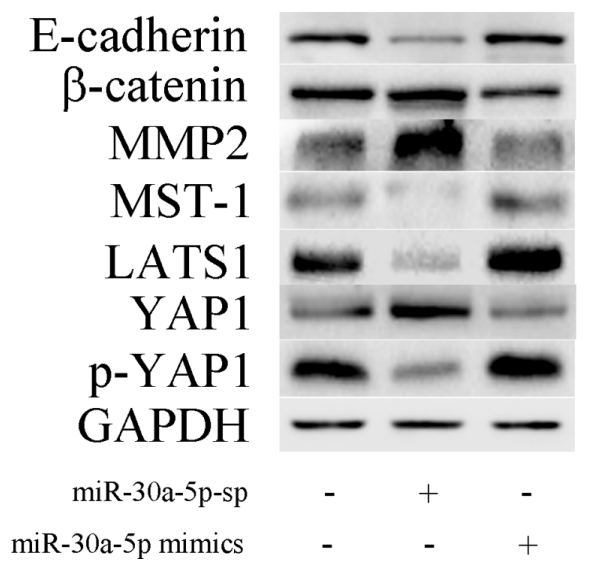

B

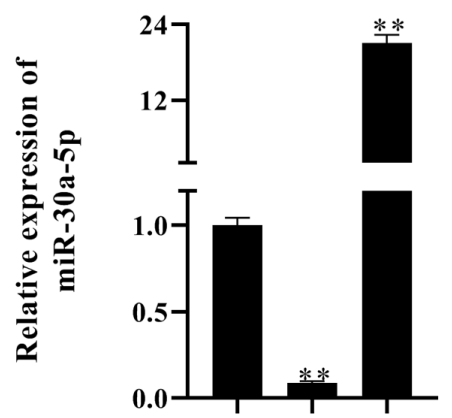

miR-30a-5p-sp miR-30a-5p mimics

D

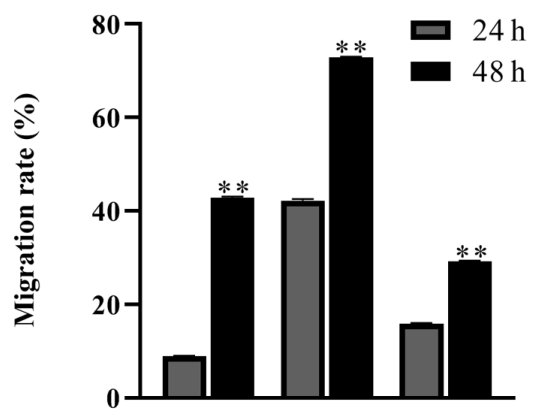

miR-30a-5p-sp

miR-30a-5p mimics

F

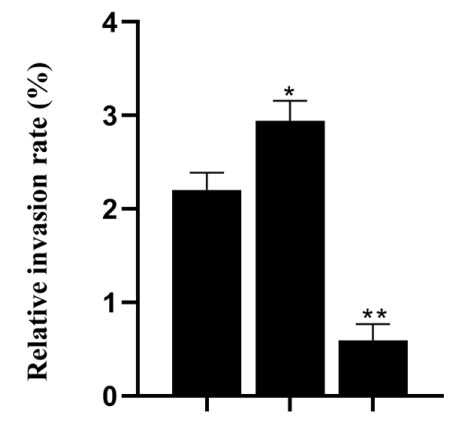

miR-30a-5p-sp miR-30a-5p mimics

$\mathrm{H}$

\section{$135 \mathrm{kDa}$ \\ $92 \mathrm{kDa}$ \\ $72 \mathrm{kDa}$ \\ $56 \mathrm{kDa}$ \\ $126 \mathrm{kDa}$ \\ $65 \mathrm{kDa}$ \\ $65 \mathrm{kDa}$ \\ $36 \mathrm{kDa}$}

Figure 3. Effects of miR-30a-5p on the Hippo and epithelial-mesenchymal transition signaling pathways in HCT116 cells. (A) HCT116 cell viability was analyzed following transfection with miR-30a-5p mimics and miR-30a-5p-sp. (B) Reverse transcription-quantitative PCR revealed that miR-30a-5p expression was markedly increased by miR-30a-5p mimics and reduced by miR-30a-5p-sp in HCT116 cells. The control group were untransfected cells, which are HCT116 cells. (C) Scratch experiments revealed that miR-30a-5p inhibited HCT116 cell migration (magnification, x40). (D) Quantitative histogram of the results of scratch experiments. (E) Transwell experiments revealed that miR-30a-5p inhibited HCT116 cell invasion (magnification, x100). (F) Quantitative histogram of the results of Transwell experiments. (G) Expression levels of YAP1, $\beta$-catenin, MMP2, E-cadherin, MST-1, LATS1 and p-YAP1 were altered by miR-30a-5p mimic transfection in HCT116 cells. (H) Semi-quantitative analysis of the results of western blotting. *P<0.05 and ** $\mathrm{P}<0.01 \mathrm{vs}$. control (HCT116 cells) or $24 \mathrm{~h}$ in (D); ${ }^{\#} \mathrm{P}<0.01$, significantly different from the miR-30a-5p-sp group. miR, microRNA; YAP1, Yes-associated protein; MST-1, mammalian STE20-like protein kinase; LATS1, large tumor suppressor kinase 1; p, phosphorylated; sp, sponge. 
A

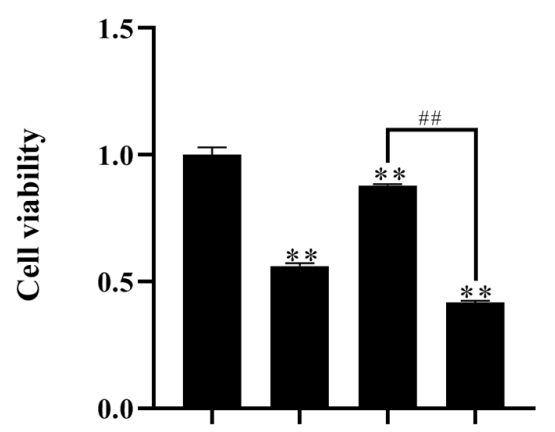

Curcumol $(50 \mu \mathrm{g} / \mathrm{ml})$

miR-30a-5p mimics

C
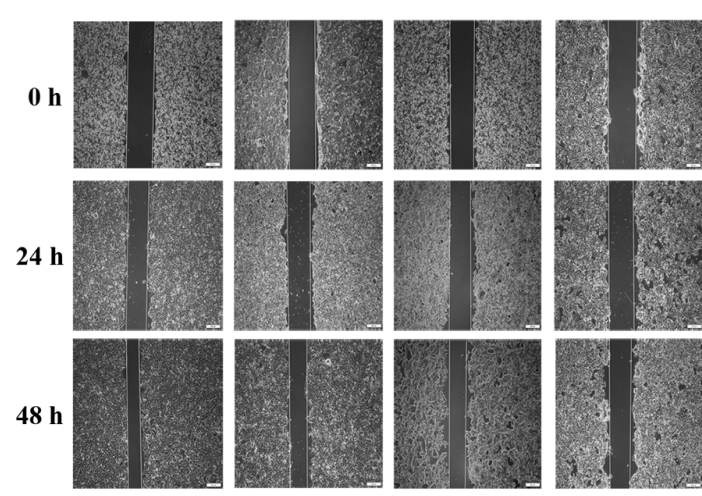

Curcumol (50 $\mu \mathrm{g} / \mathrm{ml})$

miR-30a-5p mimics

E
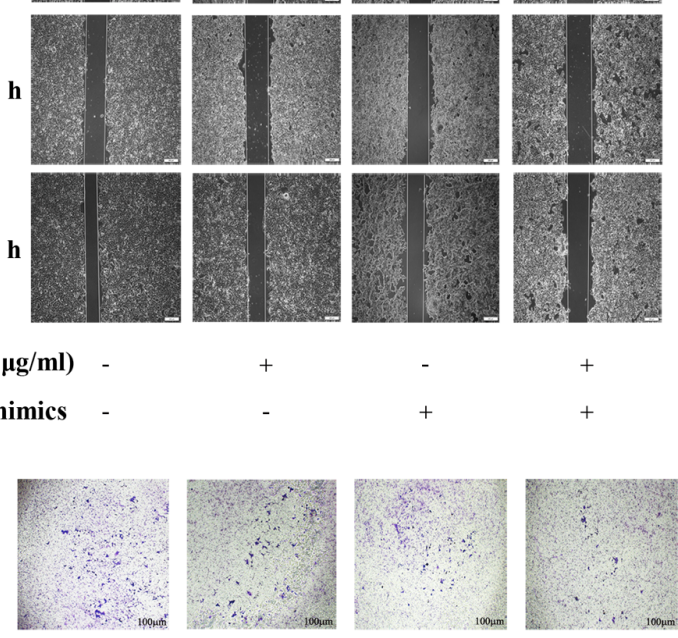

Curcumol (50 $\mu \mathrm{g} / \mathrm{ml}) \quad-$

miR-30a-5p mimics
B

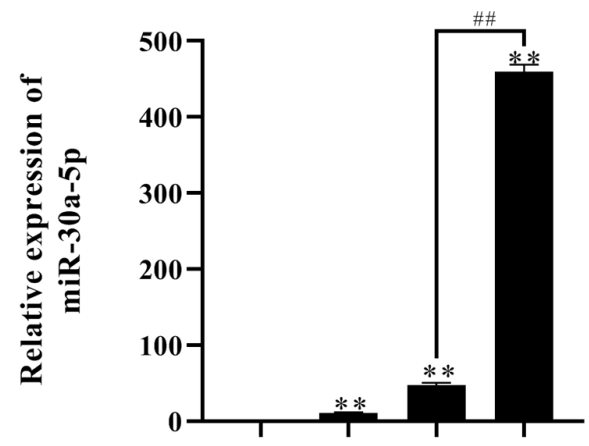

Curcumol (50 $\mu \mathrm{g} / \mathrm{ml})$

miR-30a-5p mimics

D

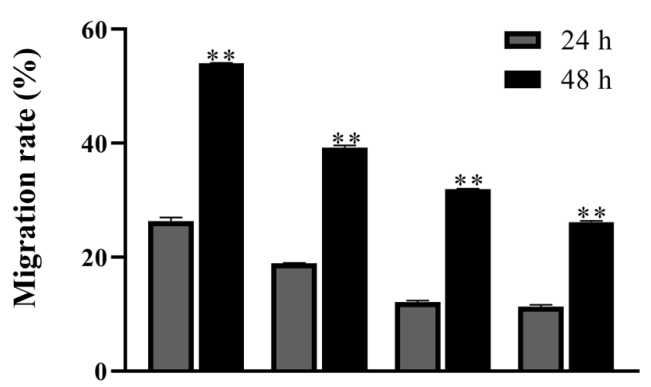

Curcumol (50 $\mu \mathrm{g} / \mathrm{ml}$ ) miR-30a-5p mimics

F

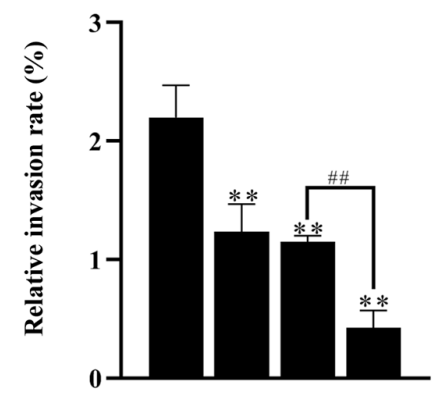

Curcumol (50 $\mu \mathrm{g} / \mathrm{ml})$ miR-30a-5p mimics

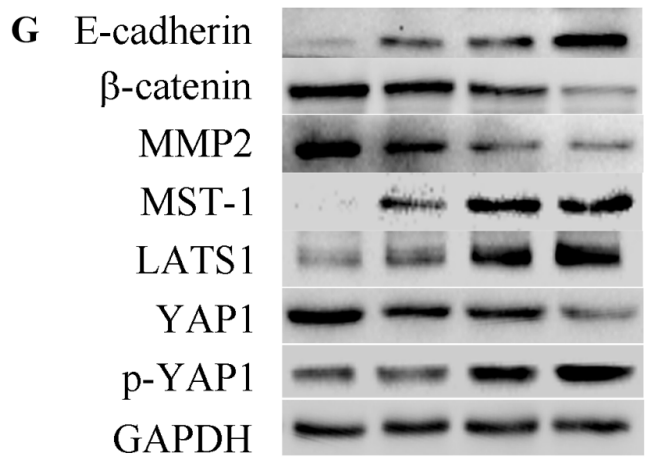

Curcumol (50 $\mu \mathrm{g} / \mathrm{ml}) \quad-\quad-\quad+\quad+$

miR-30a-5p mimics

\section{$135 \mathrm{KDa}$ \\ $92 \mathrm{KDa}$ \\ $72 \mathrm{KDa}$ \\ $56 \mathrm{KDa}$ \\ $126 \mathrm{KDa}$ \\ $65 \mathrm{KDa}$ \\ $65 \mathrm{KDa}$ \\ $36 \mathrm{KDa}$}

H

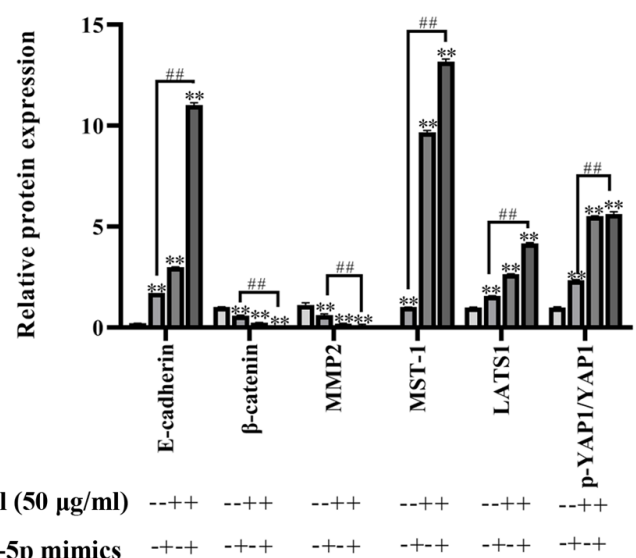

Figure 4. miR-30a-5p enhances the inhibitory effects of curcumol on the Hippo and epithelial-mesenchymal transition signaling pathways in HCT116 cells. (A) HCT116 cell viability was decreased in curcumol- and miR-30a-5p mimic-treated groups. (B) miR-30a-5p expression was increased in curcumol- and miR-30a-5p-mimic-treated groups. (C) Scratch experiments revealed that curcumol inhibited the migration of HCT116 cells by upregulating miR-30a-5p (magnification, x40). (D) Quantitative histogram of the results of scratch experiments. (E) Transwell experiments revealed that curcumol inhibited the invasion of HCT116 cells by upregulating miR-30a-5p (magnification, x100). (F) Quantitative histogram of the results of Transwell experiments. (G) Expression levels of YAP1, $\beta$-catenin, MMP2, E-cadherin, MST-1, LATS1 and p-YAP1 in HCT116 cells following treatment with curcumol and miR-30a-5p mimics were detected by western blotting. (H) Semi-quantitative analysis of the results of western blotting. ${ }^{* *} \mathrm{P}<0.01 \mathrm{vs}$. control (miR-30a-5p mimics-NC) or $24 \mathrm{~h}$ in (D); ${ }^{\# \#} \mathrm{P}<0.01$. miR, microRNA; YAP1, Yes-associated protein; MST-1, mammalian STE20-like protein kinase; LATS1, large tumor suppressor kinase 1; p, phosphorylated. 
A

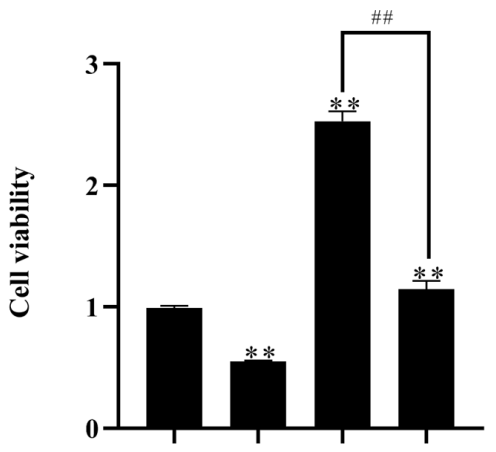

C
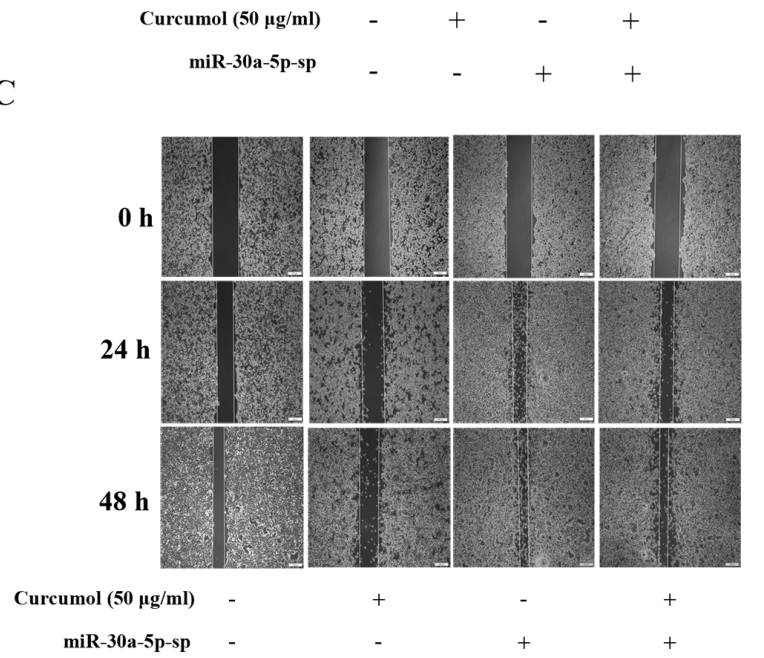

E

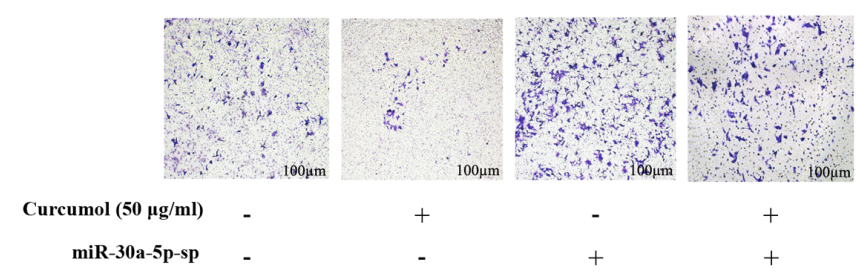

G

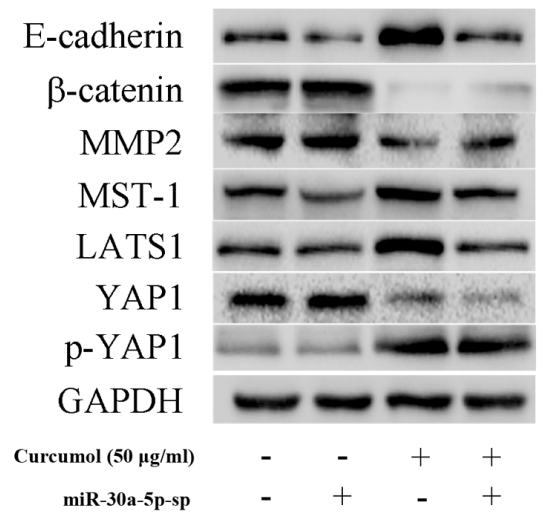

B

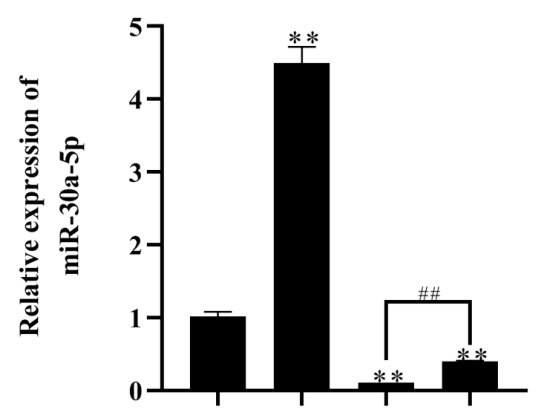

D

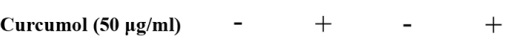

miR-30a-5p-sp $\quad-\quad+\quad+\quad+$

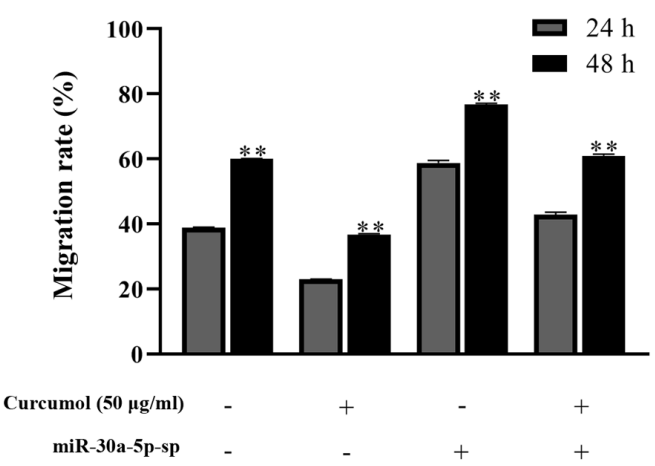

F

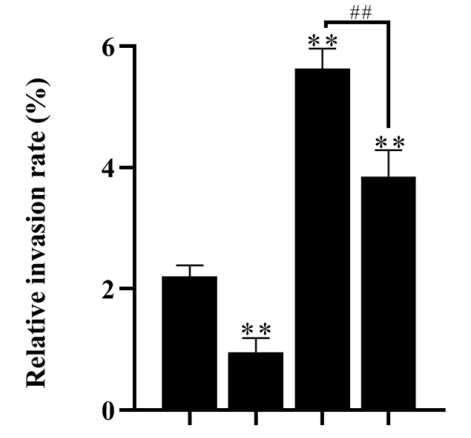

Curcumol (50 $\mu \mathrm{g} / \mathrm{ml}) \quad-\quad+\quad-\quad+$

miR-30a-5p-sp $\quad$ - $\quad$ - $\quad+\quad+$

H

$135 \mathrm{KDa}$

$92 \mathrm{KDa}$

$72 \mathrm{KDa}$

$56 \mathrm{KDa}$

$126 \mathrm{KDa}$

$65 \mathrm{KDa}$

$65 \mathrm{KDa}$

$36 \mathrm{KDa}$

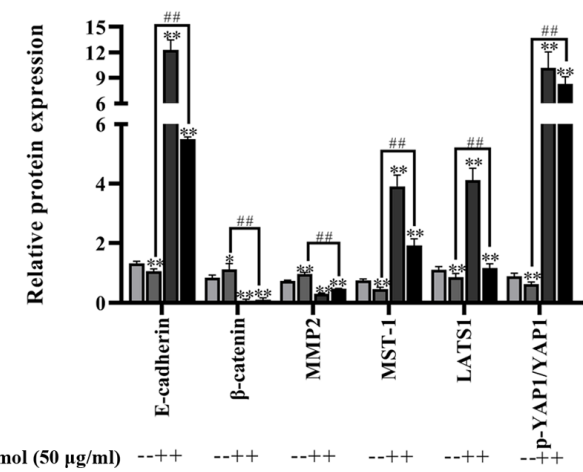

$\begin{array}{llllllll}\text { miR-30a-5p-sp } & -+-+ & -+-+ & -+-+ & -+-+ & -+-+ & -+-+\end{array}$

Figure 5. Downregulation of miR-30a-5p reverses the effects of curcumol on CRC cell epithelial-mesenchymal transition and the Hippo signaling pathway. (A) HCT116 cell viability was analyzed using an MTT assay following treatment with curcumol and/or miR-30a-5p-sp. (B) Reverse transcription-quantitative PCR was performed to detect miR-30a-5p expression in HCT116 cells treated with curcumol and/or miR-30a-5p-sp. (C) Scratch experiments revealed that the inhibitory effects of curcumol on migration were decreased in HCT116 cells following downregulation of miR-30a-5p (magnification, x40). (D) Quantitative histogram of the results of scratch experiments. (E) Transwell experiments revealed that the inhibitory effects of curcumol on invasion were decreased in HCT116 cells following downregulation of miR-30a-5p (magnification, x100). (F) Quantitative histogram of the results of Transwell experiments. (G) Expression levels of YAP1, $\beta$-catenin, MMP2, E-cadherin, MST-1, LATS1 and p-YAP1 in HCT116 cells were detected by western blotting following treatment with curcumol and/or miR-30a-5p-sp. (H) Semi-quantitative analysis of the results of western blotting. ${ }^{*} \mathrm{P}<0.05$ and ${ }^{* *} \mathrm{P}<0.01$ vs. control (miR-30a-5p-sp $\mathrm{NC}$ ) or $24 \mathrm{~h}$ in (D); ${ }^{\# \#} \mathrm{P}<0.01$. miR, microRNA; YAP1, Yes-associated protein; MST-1, mammalian STE20-like protein kinase; LATS1, large tumor suppressor kinase $1 ;$ p, phosphorylated; sp, sponge. 
A

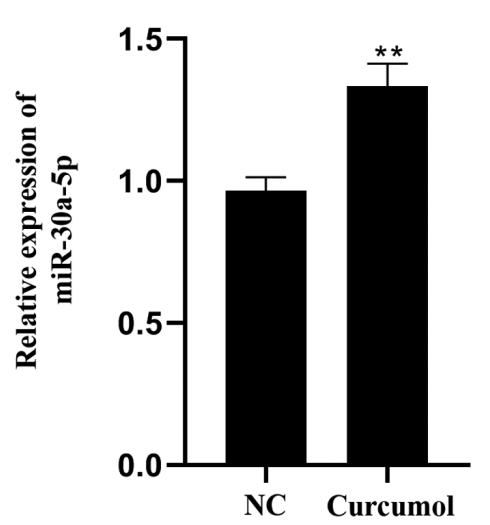

B

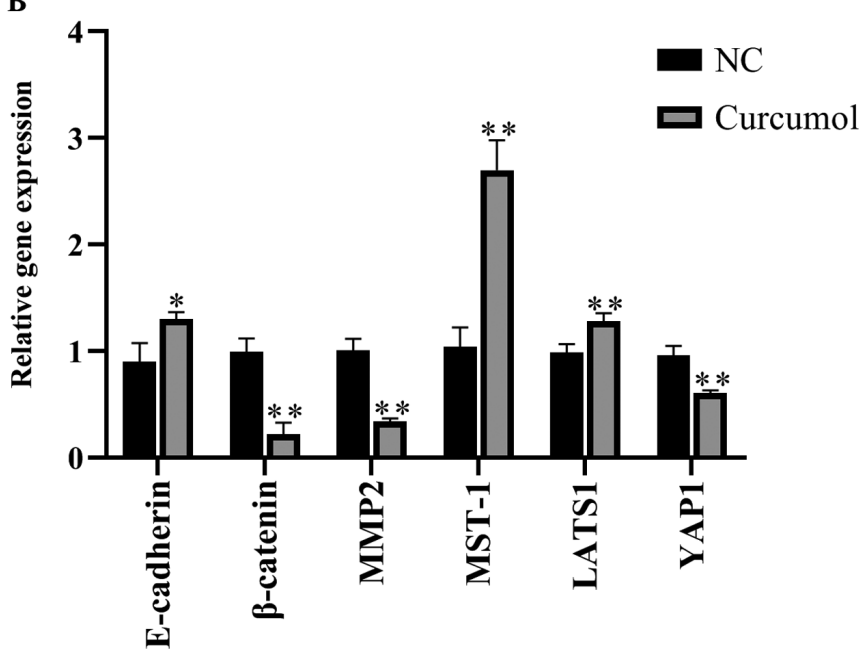

Figure 6. Curcumol can regulate the expression levels of miR-30a-5p and the Hippo signaling pathway in vivo. (A) Curcumol treatment increased the expression levels of miR-30a-5p. (B) Curcumol increased the expression levels of E-cadherin, MST-1 and LATS1, and inhibited YAP1, $\beta$-catenin and MMP2 expression. ${ }^{*} \mathrm{P}<0.05$ and ${ }^{* *} \mathrm{P}<0.01$ vs. NC. miR, microRNA; YAP1, Yes-associated protein; MST-1, mammalian STE20-like protein kinase; LATS1, large tumor suppressor kinase 1 ; NC, negative control.

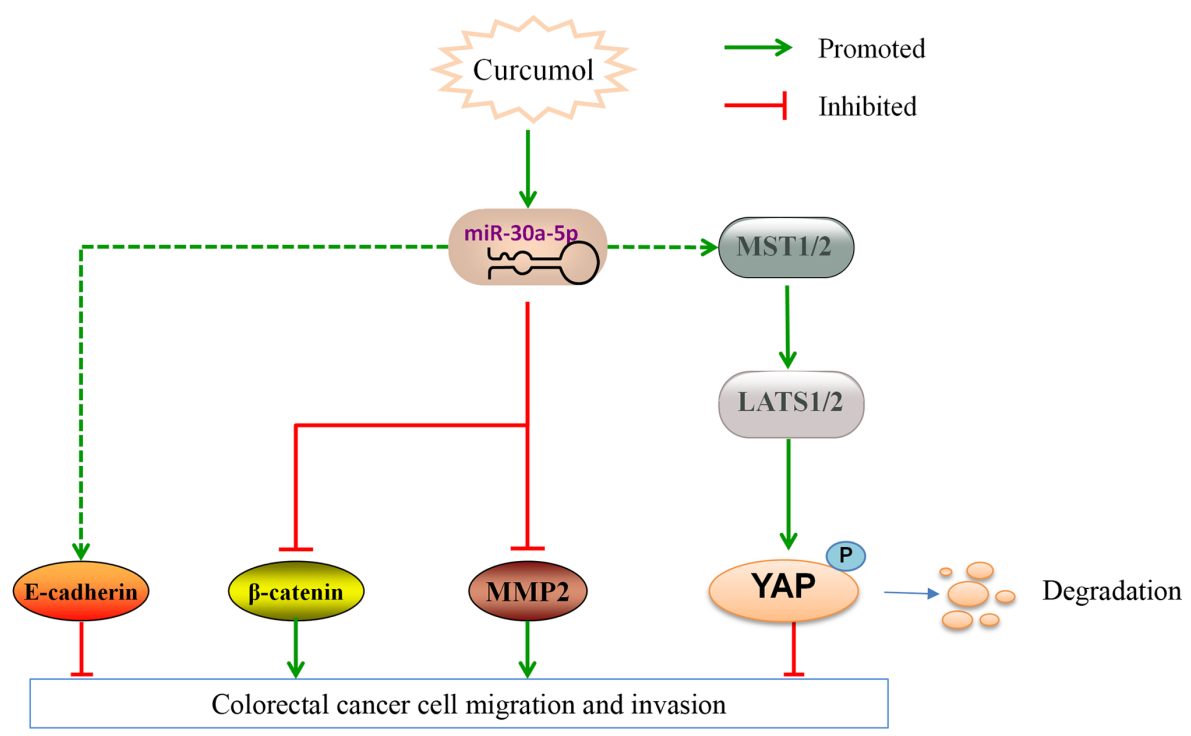

Figure 7. Experimental framework. Curcumol treatment increased miR-30a-5p expression, promoted the expression of E-cadherin, activated the Hippo signaling pathway, and inhibited $\beta$-catenin and MMP2 expression. miR, microRNA; YAP1, Yes-associated protein; MST-1, mammalian STE20-like protein kinase; LATS1, large tumor suppressor kinase 1; p, phosphorylated.

$(50 \mu \mathrm{g} / \mathrm{ml})$ on the expression levels of YAP1, $\beta$-catenin and MMP2, and increased the promoting effects of curcumol on the expression levels of E-cadherin, MST-1, LATS1 and p-YAP1 in HCT116 cells, and the difference between curcumol and no curcumol in cells treated with miR-30a-5p mimics was significant (Fig. 4G and $\mathrm{H}$ ). The results indicated that the effect of curcumol on CRC cell invasion and the Hippo signaling pathway was associated with miR-30a-5p upregulation.

Downregulation of miR-30a-5p reverses the effects of curcumol on invasion and the Hippo signaling pathway. In addition to overexpressing miR-30a-5p in HCT116 cells, the present study also inhibited its expression in HCT116 cells and observed whether the effects of curcumol on the invasion and migration of HCT116 cells were altered. MTT assays demonstrated that curcumol $(50 \mu \mathrm{g} / \mathrm{ml})$ inhibited HCT116 cell viability, and miR-30a-5p-sp promoted HCT116 cell viability. Following treatment with both miR-30a-5p-sp and curcumol simultaneously, HCT116 cell viability was significantly inhibited compared with that in the group treated with miR-30a-5p-sp alone (Fig. 5A). RT-qPCR revealed that the expression levels of miR-30a-5p were downregulated following treatment with miR-30a-5p-sp. The expression levels of miR-30a-5p were upregulated following treatment with curcumol $(50 \mu \mathrm{g} / \mathrm{ml})$. When miR-30a-5p-sp and curcumol $(50 \mu \mathrm{g} / \mathrm{ml})$ were used simultaneously, the expression levels of miR-30a-5p were higher than in the group treated with miR-30a-5p-sp alone (Fig. 5B). Scratch assays demonstrated that miR-30a-5p-sp promoted HCT116 cell migration, while curcumol $(50 \mu \mathrm{g} / \mathrm{ml})$ inhibited HCT116 cell migration. Following treatment with both miR-30a-5p-sp 
and curcumol simultaneously, HCT116 cell migration was inhibited compared with that of the miR-30a-5p-sp group, and HCT116 cell migration was increased at $48 \mathrm{~h}$ compared with $24 \mathrm{~h}$ (Fig. 5C and D). Transwell assays demonstrated that miR-30a-5p-sp promoted HCT116 cell invasion, while curcumol $(50 \mu \mathrm{g} / \mathrm{ml})$ inhibited HCT116 cell invasion. Following treatment with both miR-30a-5p-sp and curcumol simultaneously, HCT116 cell invasion was inhibited compared with that of the miR-30a-5p-sp group (Fig. 5E and F). Western blotting demonstrated that when miR-30a-5p-sp was transfected into HCT116 cells, the expression levels of YAP1, $\beta$-catenin and MMP2 were increased, and the levels of E-cadherin, MST-1, LATS1 and p-YAP1 were decreased. However, curcumol treatment decreased the expression levels of YAP1, $\beta$-catenin and MMP2, and increased the levels of E-cadherin, MST-1, LATS1 and p-YAP1. Following treatment with both miR-30a-5p-sp and curcumol simultaneously, YAP1, $\beta$-catenin and MMP2 expression was decreased, while the levels of E-cadherin, MST-1, LATS1 and p-YAP1 in HCT116 cells were increased compared with those in the group treated with miR-30a-5p-sp alone (Fig. 5G and $\mathrm{H}$ ).

Curcumol can regulate the expression levels of miR-30a-5p and the Hippo signaling pathway in vivo. A xenograft tumor model of CRC was established. RT-qPCR revealed that curcumol $(40 \mu \mathrm{g} / \mathrm{ml})$ treatment increased miR-30a-5p expression, increased the expression levels of E-cadherin, MST-1, LATS1 and p-YAP1, and inhibited YAP1, $\beta$-catenin and MMP2 expression (Fig. 6).

\section{Discussion}

CRC is a common gastrointestinal tumor with high invasion rates, which causes significant mortality $(24,25)$. Therefore, it is urgent to identify novel treatments and to explore effective therapeutic targets for CRC invasion. Increasing numbers of non-coding RNAs have been identified as CRC prognostic biomarkers and novel therapeutic targets (26-28). Increasing evidence has indicated that miRNA expression is abnormal in various types of cancer, and that miRNAs act as tumor suppressors or promoters $(29,30)$. It has been demonstrated that miR-30a-5p expression is decreased in a number of cancer types and may be a novel potential prognostic biomarker or molecular therapeutic target for $\operatorname{GBC}$ and $\operatorname{CRC}(8,31)$. Although miR-30a-5p has been demonstrated to be a tumor suppressor, and suppresses CRC cell migration and invasion by targeting ITGB3 and may be a promising therapeutic target for CRC (10), few drugs, particularly natural drugs, have been reported to inhibit CRC cell invasion by increasing its expression. The present study investigated the potential effects of curcumol on miR-30a-5p expression, and CRC cell migration and invasion. It was demonstrated that curcumol increased miR-30a-5p expression in CRC cells, and overexpression of miR-30a-5p enhanced the effects of curcumol on CRC cell migration and invasion, while downregulation of miR-30a-5p reversed its effects on CRC cells.

In addition, the present study revealed the association between miR-30a-5p and the Hippo signaling pathway. The Hippo signaling pathway is dysregulated in numerous types of cancer, including CRC (32-34). Its inactivation is associated with CRC progression (35-37). YAP is a major effector in the Hippo signaling pathway and p-YAP exists in the cytoplasm. When the Hippo signaling pathway is activated, YAP remains in the cytoplasm in the phosphorylated form, and YAP mediates the expression of multiple downstream genes to control tissue development and progress (38). It has been demonstrated that the EMT signaling pathway can be regulated by YAP (39). When the EMT process is activated, the expression of epithelial marker E-cadherin, which serves a key role in attachment, is inhibited (40), whereas $\beta$-catenin, a mesenchymal protein marker, is activated $(41,42)$. The EMT signaling pathway is further complicated by interactions with matrix metalloproteinases. Among these complex interactions, MMP2 and other MMPs have been demonstrated to promote EMT, which is involved in cancer invasion $(43,44)$. The present study revealed that increased miR-30a-5p expression following curcumol treatment inhibited CRC cell invasion, migration and MMP2 expression, and activated the Hippo signaling pathway. In addition, overexpression of miR-30a-5p activated the Hippo signaling pathway and enhanced the effect of curcumol on its downstream factors, such as MST-1, LATS1 and YAP1. Furthermore, downregulation of miR-30a-5p expression inhibited the activation of the Hippo signaling pathway and reversed the stimulatory effects of curcumol on this signaling pathway (Fig. 7).

In summary, these results suggested that miR-30a-5p can be used as a therapeutic target for CRC treatment and may be associated with the activation of the Hippo signaling pathway. Curcumol inhibited viability, migration and invasion by regulating miR-30a-5p expression and activating the Hippo signaling pathway in CRC cells, and curcumol may be a promising agent for the treatment of CRC.

\section{Acknowledgements}

Not applicable.

\section{Funding}

The present study was supported by the National Natural Science Foundation of China (grant nos. 81760443 and 81760663), Guangxi SpecialFund Project for Innovation-Driven Development (grant no. GuikeAA19254025), the Project of Guangxi Natural Science Foundation (grant no. 2017GXNSFDA198029), the Fourth Batch of Bagui Scholars' Special Funds for 2017 [grant no. (2017) 143], the Small Talent Highland Fund in Guangxi (grant no. 201707), the Scientific Research and Technology Development Program of Guilin (grant no. 20170109-38), and Basic Ability Improvement Project for Young and Middle-aged People of Guangxi Education Department (grant no. 2020KY12030).

\section{Availability of data and materials}

The datasets used and/or analyzed during the current study are available from the corresponding author on reasonable request.

\section{Authors' contributions}

DY, HL, JW and XC provided experimental ideas. DY, HL, JW, JQ, MH and XC edited the graphics. DY, HL, JW, JQ, 
MH, XG, XL, LW, MF, LZ, TD, YL and XC participated in completing the experiments. DY, HL, JW and $\mathrm{XC}$ wrote and revised the manuscript. JW and XC confirm the authenticity of all the raw data. All authors read and approved the final manuscript.

\section{Ethics approval and consent to participate}

All samples were studied with the written consent of the patient and approval of Guilin Medical College Ethics Committee (Guilin, China).

\section{Patient consent for publication}

Not applicable.

\section{Competing interests}

The authors declare that they have no competing interests.

\section{References}

1. Flemer B, Warren RD, Barrett MP, Cisek K, Das A, Jeffery IB, Hurley E, O'Riordain M, Shanahan F and O'Toole PW: The oral microbiota in colorectal cancer is distinctive and predictive. Gut 67: 1454-1463, 2018.

2. Bray F, Ferlay J, Soerjomataram I, Siegel RL, Torre LA and Jemal A: Global cancer statistics 2018: GLOBOCAN estimates of incidence and mortality worldwide for 36 cancers in 185 countries. CA Cancer J Clin 68: 394-424, 2018.

3. Yao P, Li Y, Shen W, Xu X, Zhu W, Yang X, Cao J and Xing C: ANKHD1 silencing suppresses the proliferation, migration and invasion of CRC cells by inhibiting YAP1-induced activation of EMT. Am J Cancer Res 8: 2311-2324, 2018.

4. Paauwe M, Schoonderwoerd MJA, Helderman RFCP, Harryvan TJ, Groenewoud A, van Pelt GW, Bor R, Hemmer DM, Versteeg HH, Snaar-Jagalska BE, et al: Endoglin expression on cancer-associated fibroblasts regulates invasion and stimulates colorectal cancer metastasis. Clin Cancer Res 24: 6331-6344, 2018.

5. Shastri AA, Saleh A, Savage JE, DeAngelis T, Camphausen K and Simone NL: Dietary alterations modulate the microRNA 29/30 and IGF-1/AKT signaling axis in breast cancer liver metastasis. Nutr Metab (Lond) 17: 23, 2020.

6. Gao D, Zhou Z and Huang H: miR-30b-3p inhibits proliferation and invasion of hepatocellular carcinoma cells via suppressing PI3K/Akt pathway. Front Genet 10: 1274, 2019.

7. Sun T, Liu Z, Zhang R, Ma S, Lin T, Li Y, Yang S, Zhang W and Wang Y: Long non-coding RNA LEF1-AS1 promotes migration, invasion and metastasis of colon cancer cells through miR-30-5p/SOX9 axis. Onco Targets Ther 13: 2957-2972, 2020.

8. Ye YY, Mei JW, Xiang SS, Li HF, Ma Q, Song XL, Wang Z, Zhang YC, Liu YC, Jin YP, et al: MicroRNA-30a-5p inhibits gallbladder cancer cell proliferation, migration and metastasis by targeting E2F7. Cell Death Dis 9: 410, 2018.

9. Wang L, Zhao S and Yu M: Mechanism of low expression of miR-30a-5p on epithelial-mesenchymal transition and metastasis in ovarian cancer. DNA Cell Biol 38: 341-351, 2019.

10. Wei W, Yang Y, Cai J, Cui K, Li RX, Wang H, Shang X and Wei D: MiR-30a-5p suppresses tumor metastasis of human colorectal cancer by targeting ITGB3. Cell Physiol Biochem 39: 1165-1176, 2016.

11. Wang X,Zhao Y,Lu Q, Fei X, Lu C,Li C and Chen H: MiR-34a-5p inhibits proliferation, migration, invasion and epithelialmesenchymal transition in esophageal squamous cell carcinoma by targeting LEF1 and inactivation of the Hippo-YAP1/TAZ signaling pathway. J Cancer 11: 3072-3081, 2020.

12. Yu S, Jing L, Yin XR, Wang MC, Chen YM, Guo Y, Nan KJ and Han LL: MiR-195 suppresses the metastasis and epithelial-mesenchymal transition of hepatocellular carcinoma by inhibiting YAP. Oncotarget 8: 99757-99771, 2017.
13. Gao Y, Yi J, Zhang K, Bai F, Feng B, Wang R, Chu X, Chen L and Song H: Downregulation of MiR-31 stimulates expression of LATS2 via the hippo pathway and promotes epithelial-mesenchymal transition in esophageal squamous cell carcinoma. J Exp Clin Cancer Res 36: 161, 2017.

14. Hashem S, Nisar S, Sageena G, Macha MA, Yadav SK, Krishnankutty R, Uddin S, Haris M and Bhat AA: Therapeutic effects of curcumol in several diseases; An overview. Nutr Cancer 14: 1-15, 2020.

15. Chun-Bin S, Yi Y, Qin-Yi W, Yang L, Jing-Ze Y, Hai-Jing X, Si-Qi Z, Jiong H, Jing W, Fei-Yu L, et al: The main active components of Curcuma zedoaria reduces collagen deposition in human lung fibroblast via autophagy. Mol Immunol 124: 109-116, 2020.

16. Chen X, Zong C, Gao Y, Cai R, Fang L, Lu J, Liu F and Qi Y: Curcumol exhibits anti-inflammatory properties by interfering with the JNK-mediated AP-1 pathway in lipopolysaccharideactivated RAW264.7 cells. Eur J Pharmacol 723: 339-345, 2014.

17. Zang S, Tang Q, Dong F, Liu H, Li L, Guo F, Pan X, Lin H, Zeng W, Cai Z, et al: Curcumol inhibits the proliferation of gastric adenocarcinoma MGC-803 cells via downregulation of IDH1. Oncol Rep 38: 3583-3591, 2017.

18. Zhang J, Su G, Tang Z, Wang L, Fu W, Zhao S, Ba Y, Bai B, Yue P, Lin Y, et al: Curcumol exerts anticancer effect in cholangiocarcinoma cells via down-regulating CDKL3. Front Physiol 9: 234, 2018.

19. Yan D, Deng S, Gan W, Li S and Li Y: Curcumol attenuates epithelial-mesenchymal transition of nasopharyngeal carcinoma cells via TGF- $\beta 1$. Mol Med Rep 17: 7513-7520, 2018.

20. Wang J, Li XM, Bai Z, Chi BX, Wei Y and Chen X: Curcumol induces cell cycle arrest in colon cancer cells via reactive oxygen species and Akt/GSK3 $\beta /$ cyclin D1 pathway. J Ethnopharmacol 210: 1-9, 2018.

21. Liu H, Wang J, Tao Y, Li X, Qin J, Bai Z, Chi B, Yan W and Chen X: Curcumol inhibits colorectal cancer proliferation by targeting miR-21 and modulated PTEN/PI3K/Akt pathways. Life Sci 221: 354-361, 2019.

22. Wang J, Huang F, Bai Z, Chi B, Wu J and Chen X: Curcumol inhibits growth and induces apoptosis of colorectal cancer LoVo cell line via IGF-1R and p38 MAPK pathway. Int J Mol Sci 16: 19851-19867, 2015.

23. Livak KJ and Schmittgen TD: Analysis of relative gene expression data using real-time quantitative PCR and the 2(-Delta Delta C(T)) method. Methods 25: 402-408, 2001.

24. Pantel K and Brakenhoff RH: Dissecting the metastatic cascade. Nat Rev Cancer 4: 448-456, 2004.

25. Cheng B, Rong A, Zhou Q and Li W: CLDN8 promotes colorectal cancer cell proliferation, migration, and invasion by activating MAPK/ERK signaling. Cancer Manag Res 11: 3741-3751, 2019.

26. Li J, Zhao LM, Zhang C, Li M, Gao B, Hu XH, Cao J and Wang GY: The IncRNA FEZF1-AS1 promotes the progression of colorectal cancer through regulating OTX1 and targeting miR-30a-5p. Oncol Res 28: 51-63, 2020.

27. Zhao H, Lai X, Zhang W, Zhu H, Zhang S, Wu W, Wang S, Tang M, Deng Z and Tan J: MiR-30a-5p frequently downregulated in prostate cancer inhibits cell proliferation via targeting PCLAF. Artif Cells Nanomed Biotechnol 47: 278-289, 2019.

28. Peng Q, Shen Y, Zhao P, Cheng M, Zhu Y and Xu B: Biomarker roles identification of miR-106 family for predicting the risk and poor survival of colorectal cancer. BMC Cancer 20: 506, 2020.

29. Zhao JJ, Lin J, Zhu D, Wang X, Brooks D, Chen M, Chu ZB, Takada K, Ciccarelli B, Admin S, et al: miR-30-5p functions as a tumor suppressor and novel therapeutic tool by targeting the oncogenic Wnt/ $\beta$-catenin/BCL9 pathway. Cancer Res 74: 1801-1813, 2014.

30. Sun ZQ, Shi K, Zhou QB, Zeng XY, Liu J, Yang SX, Wang QS, Li Z, Wang GX, Song JM, et al: MiR-590-3p promotes proliferation and metastasis of colorectal cancer via Hippo pathway. Oncotarget 8: 58061-58071, 2017.

31. Sun Y, Yang B, Lin M, Yu H, Chen H and Zhang Z: Identification of serum miR-30a-5p as a diagnostic and prognostic biomarker in colorectal cancer. Cancer Biomark 24: 299-305, 2019.

32. Ren L, Zhang Z, Feng Y, Luo M and Hao Z: MicroRNA-876-5p represses the cell proliferation and invasion of colorectal cancer through suppressing YAP signalling via targeting RASAL2. Clin Exp Pharmacol Physiol 47: 867-876, 2020.

33. Zhao H, Huang A, Li P, Quan Y, Feng B, Chen X, Mao Z, Zhu $Z$ and Zheng M: E2A suppresses invasion and migration by targeting YAP in colorectal cancer cells. J Transl Med 11: 317, 2013. 
34. Cheng D, Jin L, Chen Y, Xi X and Guo Y: YAP promotes epithelial mesenchymal transition by upregulating Slug expression in human colorectal cancer cells. Int J Clin Exp Pathol 13: 701-710, 2020.

35. Wang L, Shi S, Guo Z, Zhang X, Han S, Yang A, Wen W and Zhu Q: Overexpression of YAP and TAZ is an independent predictor of prognosis in colorectal cancer and related to the proliferation and metastasis of colon cancer cells. PLoS One 8: e65539, 2013.

36. Xu Z, Wang H, Gao L, Zhang H and Wang X: YAP levels combined with plasma CEA levels are prognostic biomarkers for early-clinical-stage patients of colorectal cancer. Biomed Res Int 2019: 2170830, 2019.

37. Ye Y, Zhang R and Feng H: Fibronectin promotes tumor cells growth and drugs resistance through a CDC42-YAP-dependent signaling pathway in colorectal cancer. Cell Biol Int 44: 1840-1849, 2020.

38. Meng Z, Moroishi T and Guan KL: Mechanisms of Hippo pathway regulation. Genes Dev 30: 1-17, 2016.

39. Chen W, Wang H, Liu Y, Xu W, Ling C, Li Y, Liu J, Chen M, Zhang $\mathrm{Y}$, Chen $\mathrm{B}$, et al: Linc-RoR promotes proliferation, migration, and invasion via the Hippo/YAP pathway in pancreatic cancer cells. J Cell Biochem 121: 632-641, 2020

40. Jolly MK, Ware KE, Xu S, Gilja S, Shetler S, Yang Y, Wang X, Austin RG, Runyambo D, Hish AJ, et al: E-cadherin represses anchorage-independent growth in sarcomas through both signaling and mechanical mechanisms. Mol Cancer Res 17: $1391-1402,2019$
41. Hu Z, Wang P, Lin J, Zheng X, Yang F, Zhang G, Chen D, Xie J, Gao Z, Peng L and Xie C: MicroRNA-197 promotes metastasis of hepatocellular carcinoma by activating $\mathrm{Wnt} / \beta$-catenin signaling. Cell Physiol Biochem 51: 470-486, 2018.

42. Yang S, Liu Y, Li MY, Ng CSH, Yang SL, Wang S, Zou C, Dong Y, Du J, Long X, et al: FOXP3 promotes tumor growth and metastasis by activating Wnt $/ \beta$-catenin signaling pathway and EMT in non-small cell lung cancer. Mol Cancer 16: 124, 2017.

43. Wang J, Cai H, Liu Q, Xia Y, Xing L, Zuo Q, Zhang Y, Chen C, $\mathrm{Xu} \mathrm{K}$, Yin $\mathrm{P}$ and Chen T: Cinobufacini inhibits colon cancer invasion and metastasis via suppressing Wnt $/ \beta$-catenin signaling pathway and EMT. Am J Chin Med 48: 703-718, 2020.

44. Hou Q, Han S, Yang L, Chen S, Chen J, Ma N, Wang C, Tang J, Chen X, Chen F, et al: The interplay of MicroRNA-34a, LGR4, EMT-associated factors, and MMP2 in regulating uveal melanoma cells. Invest Ophthalmol Vis Sci 60: 4503-4510, 2019.

This work is licensed under a Creative Commons Attribution-NonCommercial-NoDerivatives 4.0 International (CC BY-NC-ND 4.0) License. 